\title{
The monitoring of technical condition of cultural heritage objects
}

\author{
Vera A. Akristiniy ${ }^{1, *}$ \\ ${ }^{1}$ Moscow State University of Civil Engineering, Yaroslavskoe shosse, 26, Moscow, 129337, Russia
}

\begin{abstract}
The article deals with the conservation of cultural heritage objects due to their potential widespread deterioration. The suggestion to solve this problem is to create an integrated system for complex monitoring of cultural heritage objects technical condition. The stages of creating a realtime monitoring system with the choice of non-destructive testing methods, the necessary instruments, and tools, the result of which is the formation of a decision-making mechanism for a particular object, are proposed. Conducting monitoring by means of modeling allows predicting the behavior of structures and the building as a whole, taking into account the implementation of restoration measures.
\end{abstract}

\section{Introduction}

The problems associated with ensuring control over the technical condition of structures of especially valuable buildings and facilities - objects of cultural heritage have always existed, and their possible solution for today is through an implementation of significant progress in innovative technologies, software, and hardware, the development of efficient algorithms collecting and processing information. One of these problems is the monitoring of cultural heritage objects technical condition in real-time.

Inspection of the technical condition of such objects is periodic in the absence of continuous monitoring of the technical condition of structures responsible for the bearing capacity of a building or structure as a whole. Due to violations of the exploitation norms, there are possible consequences associated with irreparable damage to the unique elements of the cultural heritage object or its structures [1].

All of the above is aggravated by the common difficulties and shortcomings of the current practice of providing monitoring of architectural monuments condition associated with the lack of a systematic approach in assessing the technical condition of structures of a single cultural heritage object, the lack or insufficiency of criterion assessments and methods for determining the technical condition of an object at any time of exploitation, complexity and the novelty of the developed and introduced technologies of complex technical condition monitoring of the constructive elements of buildings and structures. Therefore, at the present time, it becomes extremely important to monitor the technical condition of cultural heritage objects in real time [2-7].

\footnotetext{
*Corresponding author: 7824666@mail.ru
} 


\section{The method of monitoring}

To develop a system for monitoring the technical condition of cultural heritage objects, it is necessary to collect baseline information, namely: to analyze the master plan, architectural and planning decisions, technical parameters of buildings, operating conditions, capital and planned repairs, surveys. Further, the monitoring of the objects technical condition is carried out selectively on individual structures, units or elements of the building, the performance of which determines the safe operation of the entire building. The purpose of the cultural heritage objects technical condition complex monitoring is accident-free and, in the long term continuous (non-stop to the survey) facility operation. Tasks of complex monitoring of the cultural heritage objects technical condition are - timely detection of defects in the structure, collection, processing, and storage of technical diagnostics data and forecasting changes in the technical state of structures over time, automating technical diagnostics and reducing the role of the human factor $[3,4]$.

The stages of creating such a system include choosing non-destructive testing methods that are optimal for solving monitoring tasks, determining the types and characteristics of sensors and other sources of objective information, developing software systems, criteria and decision-making systems, developing and manufacturing the hardware part of the system, drawing up recommendations for actions in critical situations.

Important elements of the complex monitoring system are the development and maintenance of databases (e-passports) of cultural heritage objects, allowing in real-time to receive information about the technical condition of the object. Constantly updated information on the technical condition of cultural heritage objects will improve the effectiveness of state supervisory and control agencies over the technical condition of objects, as well as predict the behavior of structures with regard to their repairs and reconstructions $[5,8]$.

The technical condition monitoring system involves the installation of various sensors on structural elements of buildings and structures in order to determine the effect of physical (humidity and ambient temperature) and force (static and dynamic loads) effects on their strength and deformation properties. Most often, wired and wireless monitoring systems are used for this purpose. The monitoring system should be capable of transmitting data from the controlled structures without their visual inspection. Measurement data from the sensors can be transmitted to the user in various ways, for example, over a radio frequency of $850-2500$ $\mathrm{Hz}$ or over wires in digital form. In the first case, wireless monitoring systems are used, and in the second case wired monitoring systems [6,9].

When using a wireless monitoring system, several sensors are connected to the network which is connected to sensor nodes that have their own independent power source $(2.5-6 \mathrm{~V})$ and can transmit independent signals over short distances, usually not more than $100 \mathrm{~m}$. Therefore, a central device is installed at the facility, which collects and stores information in a database for analysis from various nodes [10]. These data are used to assess the current state of structures, and in the event of a critical situation, a message is issued in the form of an alarm. The central unit also calibrates the sensors and provides reprogramming of the sensor nodes, generally keeping the system flexible. The central unit includes a computer with a constant power source and the corresponding programs. A schematic diagram of the wireless monitoring system is shown in Fig. 1 [11]. 


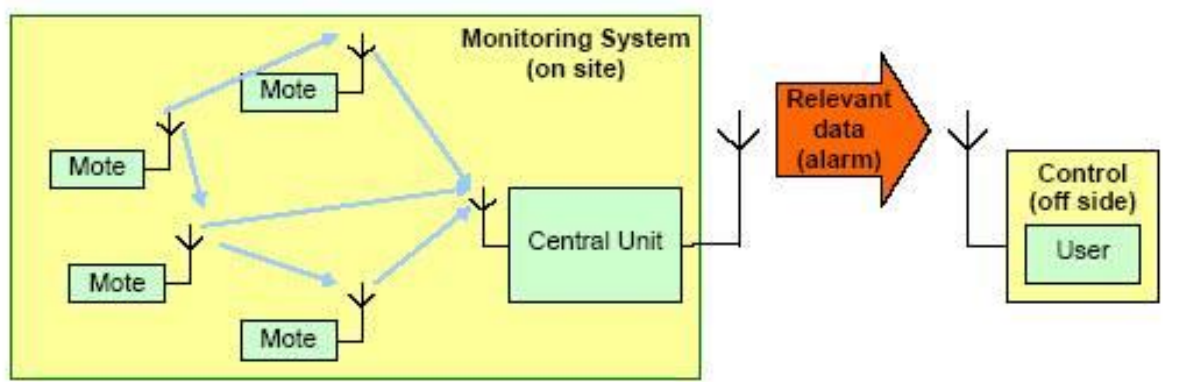

Fig. 1. Schematic diagram of the wireless monitoring system.

When using a wired monitoring system, the sensors are connected to modules that convert analog signals from sensors into digital form and transmit them further by wire to a central server. The applied fan architecture ("hub and spokes") of a wired monitoring system includes remote sensors connected by wires to the central data acquisition system (Fig. 2) and a computer.
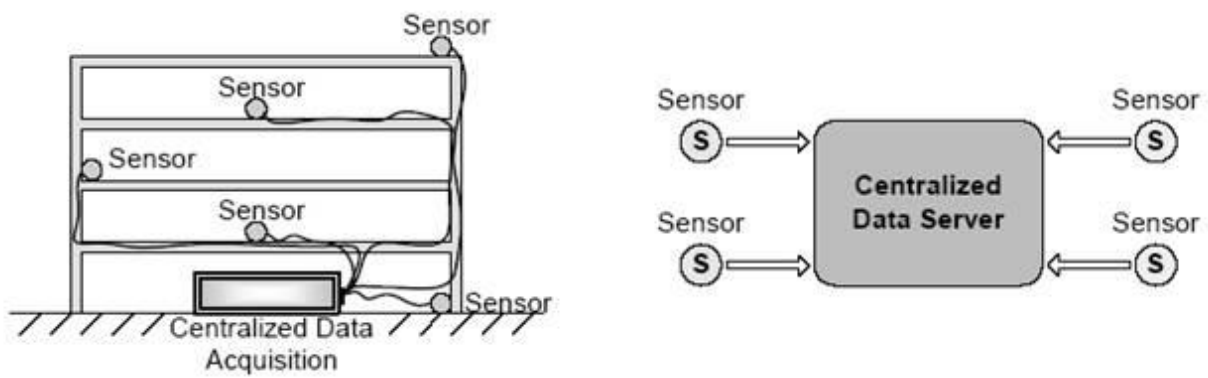

Fig. 2. The centralized wired monitoring system for building structures.

The advantage of a wireless monitoring system is its quick installation on buildings or structures, since no wiring is required. The main disadvantage of such monitoring systems is the regular need to replace the power sources of batteries and accumulators. As a rule, the duration of the power supply of such systems does not exceed several days. Recently, special algorithms have been applied to reduce power consumption, but so far, this problem has not been satisfactorily solved. The second disadvantage of wireless systems is the possibility of losing some of the information during its transmission over radio frequency due to the influence of interference in the environment. The range of information transfer does not exceed 30-70m, which also limits the use of these systems [12].

The technical condition monitoring system provides execution of the following functions:

1. Periodic monitoring of the stress-strain state of structures, the issuance of information about the location of the measured values to the design values of strength and deformation.

2. When the measured values of stresses and deformations exceeds the design values, the system continuously monitors the stress-strain state of the supporting structures, generates danger signals, and provides information about the location of the exceeded design values of strength and deformation.

3. Automatic registration of events in the system's RAM, issuing reports on events in accordance with the request, and when the occurrence of events under clause 2 automatically. 
The main component of the monitoring system is the device for collecting signals from the sensors of deformation, temperature, movement, tilt and transfer them in digital form to a computer. Sensors are placed in the most loaded structural elements.

Technical tools for instrumental research, display, storage, and processing of information on the state of enclosing structures and engineering systems of real estate objects, as a rule, include:

- measuring components of the monitoring system, types class and titles, which are selected separately for each investigated element of a building or structure;

- connecting components of the monitoring system, wired and wireless communication lines of the Ethernet standard (using mobile diagnostic laboratories), standard telephone switched channels, radio channels via radio modems;

- computational components of the monitoring system, which consist of a data collection server and automated workplaces (AWS) for the operator and administrator with software for processing the results of observations and diagnostics of the state of the building or structure elements (Fig. 3)

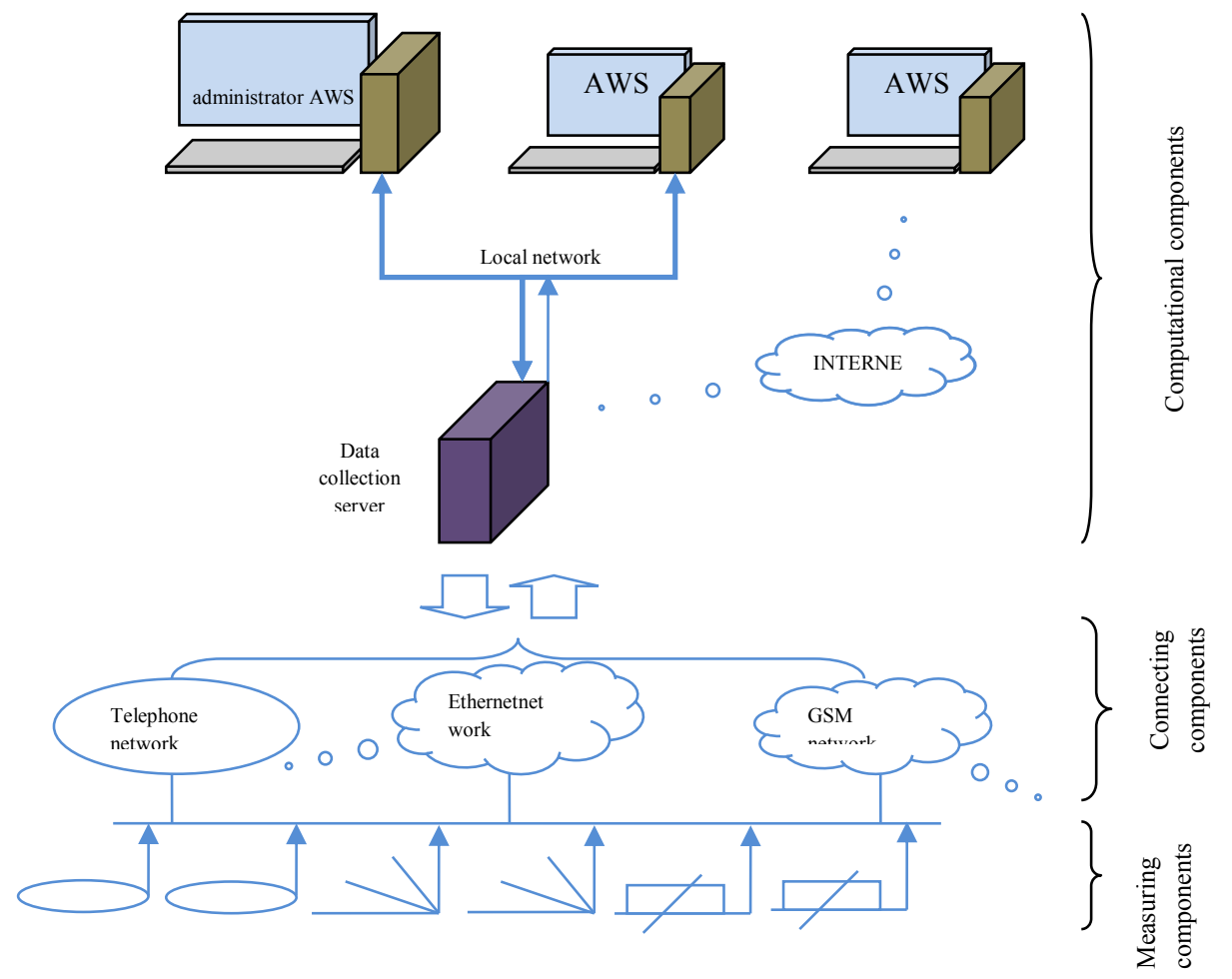

Fig. 3. The structure of technical means of monitoring the state of the elements of a building or structure.

The automated workplace should implement the final measurement transformations, computational and logical operations provided for by the monitoring program and the algorithms for processing the measurement results, up to the development of management decisions. As a rule, an automated workplace is created on the basis of a personal computer that provides tracking of the monitoring system state, analysis of the system behavior, a printout of reports and transfer of information according to the hierarchical structure. Computational components can operate both under the control of the operator and autonomously. The server and/or automated workplace throughout the hierarchical structure of the monitoring is manufactured on the basis of PC and standard electronic modules [13]. 
The computational and logical operations performed by the program and the algorithm for processing the results of observation and diagnostics of the technical condition of structural elements and engineering systems are carried out in the sequence shown in Fig.4.

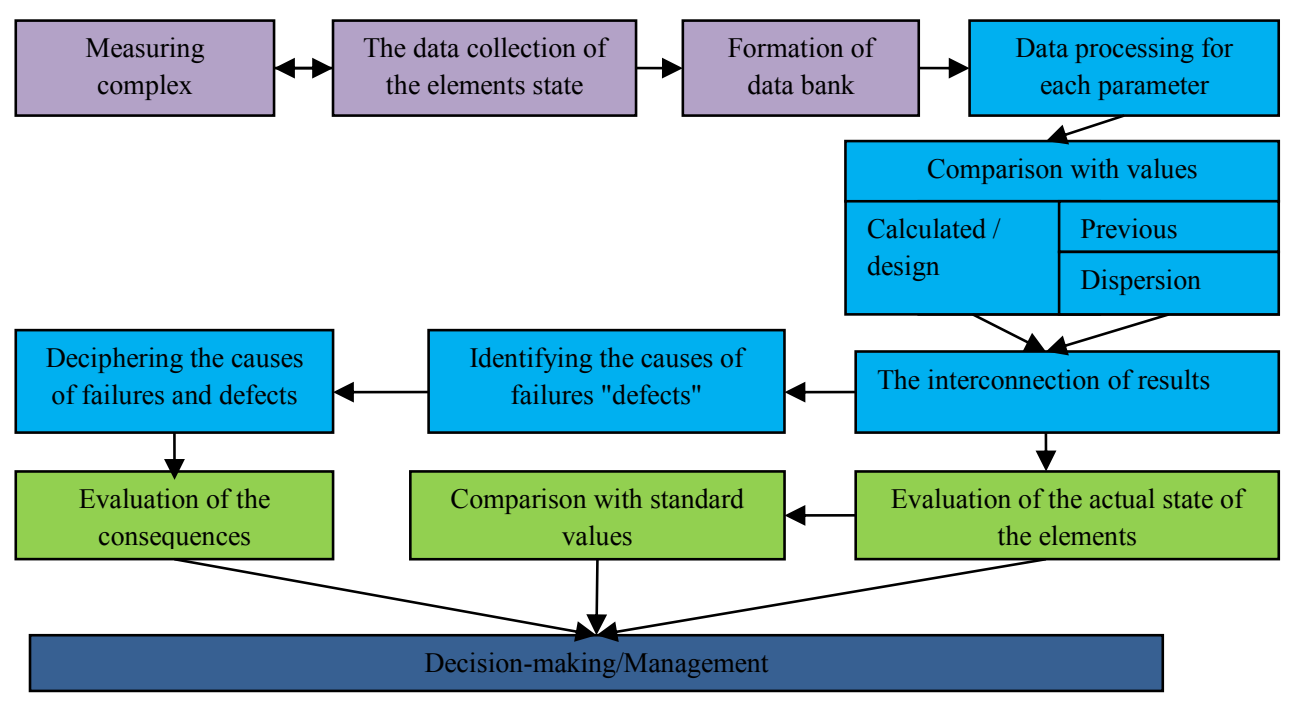

Fig. 4. Program and algorithm computing complex.

Such programs provide transfer of information from paper to digital media, storage and authentication information for the monitoring, administration, and other functions.

\section{Practical results}

The system as a whole works as follows $[14,16]$.

Stage 1. The signals from the sensors are read by the acquisition device in analog form, then converted to digital form and transmitted via cable to the computer database. A computer using specialized programs performs managing the network of sensors. Using a computer, using calibration dependencies, digital signals are converted into physical quantities: voltages, $\mathrm{kPa}$; stress, $\mathrm{kN}$; displacements, $\mathrm{mm}$; angle, deg.

Stage 2. Next, a static calculation of the structural scheme of the building is performed; the results of the calculations are entered into a computer database.

Stage 3. The measured values of stresses and strains (stage 1) are compared with the calculated values (stage 2). In case of exceeding the calculated values over the normative, an alarm message is issued (Fig. 5).

Thus, the organization of system monitoring is provided, which allows detecting violations of the operating characteristics of structures as they occur, and promptly eliminate them. Monitoring is an organizational and technical system that performs the following tasks [15]:

- collection and dissemination of reliable and timely information on the technical condition of building structures and engineering infrastructure;

- analysis of information to assess the impact of environmental factors on the state of housing and communal services;

- development of recommendations for repair projects of buildings and engineering infrastructure.

The following requirements are imposed on the monitoring of the technical condition of enclosing structures and engineering systems of real estate objects [17]: 
- reliability of monitoring - the use of information data and a system of monitored indicators that most fully and reliably characterize the object of study;

- efficiency - focus on reducing the time of collecting and processing information with the aim of making emergency management decisions, if required by the condition of the building or structure elements;

- systematic - monitoring for a more or less long period of time with certain intervals for collecting information.;

- complexity - simultaneous tracking of the indication dynamics obtained by visualinstrumental and instrumental methods, followed by verification calculations;

- independence and objectivity.

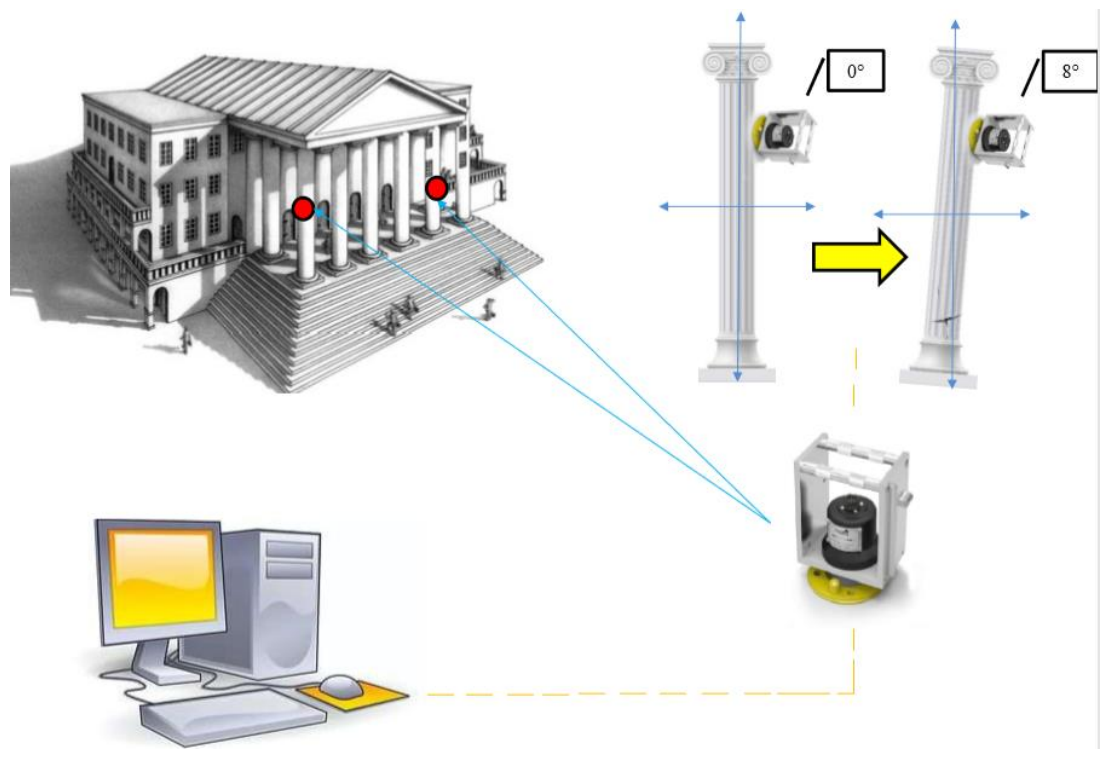

Fig. 5. Visualization of the wireless monitoring system.

When forming the monitoring information base, it is necessary to rely on the existing monitoring, control, diagnostics, and accounting systems, such as:

- dispatching services that collect real-time information about working engineering systems (heating, water supply, lighting, elevators, escalators, etc.);

- automated dispatching systems, commercial accounting, and regulation of energy consumption and others, to which it is advisable to connect the technical condition monitoring tools of the other structural elements and engineering systems of real estate objects.

For the formation of a complex monitoring system within the framework of the tasks decisions, systematized tool instrumental base, configured to determine the set parameters (table.1) [18].

Monitoring the technical condition of the objects was carried out by the method of modeling. Modeling allows you to predict the behavior of both individual elements and the entire building for different periods of time - 25, 50, 100 years, taking into account the changing adverse defects.

Complex application of the above methods enables tracking of various monitored parameters of objects with high accuracy for predetermined time slots (Fig. 6). 


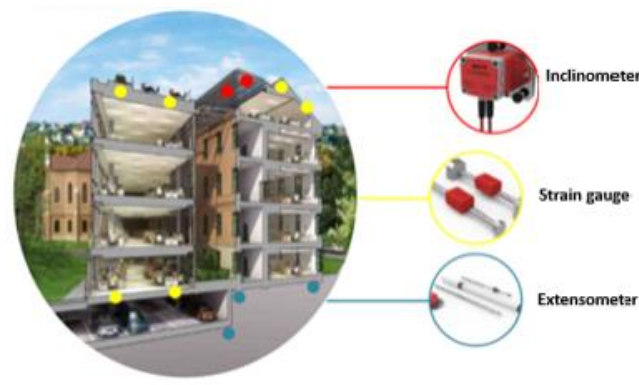

a)

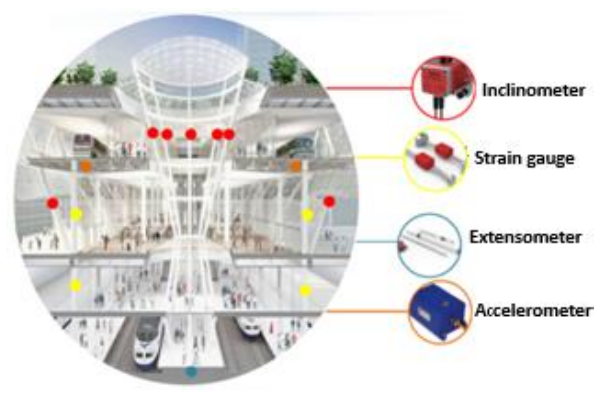

b)

Fig. 6. Examples of measurement devices for monitoring deformation processes a) for public buildings, b) for residential buildings.

Table 1. Nondestructive testing devices for technical condition monitoring.

\begin{tabular}{|l|l|}
\hline Magnet extensometer & $\begin{array}{l}\text { The magnetic extensometer is a system } \\
\text { based on the British construction } \\
\text { research method for measuring both } \\
\text { precipitations and lifting at different } \\
\text { depths in the ground, foundations. }\end{array}$ \\
\hline Tapeextensometer & $\begin{array}{l}\text { Inclinometer probe measures the } \\
\text { deviations from the vertical inside the } \\
\text { vertical casing. This makes it possible } \\
\text { to control the transverse displacement } \\
\text { of the soil. }\end{array}$ \\
\hline Holtage sensor & $\begin{array}{l}\text { The tape extensometer is designed for } \\
\text { accurate measurements of the distance } \\
\text { between two permanently installed, } \\
\text { reference points. }\end{array}$ \\
\hline Hydraulicloadsensors & $\begin{array}{l}\text { Vibration (frequency) voltage sensors } \\
\text { are used to monitor stresses in steel or } \\
\text { reinforced concrete and concrete } \\
\text { structures. }\end{array}$ \\
\hline $\begin{array}{l}\text { Hydraulic pressure sensors are } \\
\text { monoligned to measure the load in } \\
\text { placement of junction of the structure } \\
\text { and the wall of the foundation pit. }\end{array}$ \\
\hline $\begin{array}{l}\text { Profiler is a hydrostatic instrument } \\
\text { foundations and structures. }\end{array}$
\end{tabular}




\section{Discussion}

Traditionally, the main monitoring tasks stand out: continuous monitoring and recording changes in the technical condition of structural components and engineering systems and equipment of buildings or structures and its comparison with standard indicators, the development of long-term plans and a variety of models to optimize control of the technical state of the real estate.

As can be seen, in the monitoring process, not only is the assessment of the actual state of the structural elements and engineering systems of the real estate object carried out on the basis of identified defects and failures, but also an assessment is made of the predicted state of the building elements and systems, taking into account the likelihood of defects and failures over time [19].

Thus, in the course of the exploitation of real estate objects, monitoring is a continuous process organized over a sufficiently long period of time. The above allows you to record the state of the enclosing structures and engineering systems of the real estate object at certain points in time and assess the trends of the processes occurring in them. The possibility of forecasting the development of negative processes makes it possible to take measures in advance that are adequate to future events, ensuring the determined indicators, parameters of the operational qualities of real estate objects laid down in the design process and implemented during construction.

It is objectively assumed that the provision of a permanent monitoring system for the technical condition will not solve all the above problems in this area. A set of measures is needed to change the current critical situation in the field of preserving cultural heritage, namely, raising the qualifications of specialists and the competence of relevant agencies protecting cultural heritage objects, ensuring that the scientific and technological progress complies with the methodological documents used in assessing the state of especially valuable objects, increasing responsibility for ensuring proper monitoring of the monuments state and carrying out timely repairs.

\section{Conclusions}

This approach allows a comparable analysis, to study the dynamic characteristics in the corresponding elements of the building or structure. The implemented programs for monitoring the technical condition of cultural heritage objects allows more quickly and efficiently solve the problem of restoring the performance indicators of structural elements and engineering systems of buildings by making optimal decisions to eliminate the defects, failures and other deviations from their stable and reliable operation, arising in them [20].

In order to most fully reflect the essence of the processes occurring in structural elements and engineering systems of a real estate object during their operation, a number of fundamental principles are laid down in the monitoring organization: purposefulness; complex assessment; approximation; consistency; representativeness; economy; maximal informativeness results; continuity of observation of the studied objects; the frequent collection of changes information; comparability of applied monitoring indicators in time.

\section{References}

1. V. Borissova, Journal of Cultural Heritage, to be published (2018)

2. F. Mangini, L. D’Alvia, M. Del Muto, L. Dinia, E. Federici, E. Palermo, Z. Del Prete, F. Frezza, Measurement 127, 308-313 (2018)

3. M.J. Varas-Muriela, R. Fortb, Building and Environment 145, 290-307 (2018) 
4. V. Lazic, M. Vadrucci, R. Fantoni, M. Chiari, A. Mazzinghi, A. Gorghinianc, Spectrochimica Acta 149, 1-14 (2018)

5. M. Caponero, R. D'Amato, A. Polimadei, G. Terranova, Measurement 125, 325-329 (2018)

6. L. Bednarski, R. Sienko, T. Howiacki, Procedia Engineering 195, 32-39 (2017)

7. V.A. Akristiniy, E.A. Dikova, Real Estate: Economics 3, 37-45 (2017)

8. V.A. Stolbova, L.I. Pavlova, Real Estate: Economics 2, 76-84 (2015)

9. P. Walczykowski, S. Pietrek, J. Jasiński, A. Orych, GIS Ostrava (00-908, Warsaw, 2010)

10. Architecture 2030, http://architecture2030.org/ (2012)

11. A. Akihiro, K. Mitsuhiro, NEC Technical Journal 7(1), 82-86 (2012)

12. O. Risbol, C. Briese, M. Doneus, A. Nesbakken, Journal of Cultural Heritage 16, 202209 (2015)

13. A.A. Kuzmichev, V.F. Loboyko, Procedia Engineering 150, 2095-2101 (2016)

14. A.Postovalova, Vestnik MGSU 1, 54-56 (2009)

15. M.G. Mustafin, V.A. Valkov, A.I. Kazantsev, Procedia Engineering 189, 729-736 (2017)

16. H. Khorasgani, G. Biswas, Applied Soft Computing 71, 396-406 (2018)

17. V.I. Bolshakov, V.E. Vaganov, Th.A. Bier, A. Bausk, I.M. Matiushenko, O.A. Ozhyshchenko, M.Yu. Popov, A.M. Sopilniak, Procedia Engineering 172, 119-126 (2017)

18. K. Bremer, M. Wollweber, F. Weigand, M. Rahlves, M. Kuhne, R. Helbig, B. Roth, Procedia Technology 26, 524-529 (2016)

19. I. Vidovszky, Procedia Engineering 164, 575-582 (2016)

20. N. Quesada-Olmo, M.J. Jimenez-Martinez, M. Farjas-Abadia, Measurement 123, 115 124 (2018) 